\section{Commentary: Are we home yet?}

\author{
Thomas A. D’Amico, MD
}

The role of pneumonectomy continues to evolve, and the outcomes of pneumonectomy are more dependent on the physiologic status of the patient, failure to rescue, the need for readmission, and surgeon and center experience than most other thoracic surgical oncologic procedures. In addition, the decision to perform pneumonectomy is one of the most difficult and important. While the operative morbidity and mortality is greater than other procedures, patients who need pneumonectomy are significantly less likely to benefit from systemic therapy and radiation therapy alone.

Numerous investigators have studied the recovery after pneumonectomy to identify strategies that could be used to improve outcomes. One common finding is that outcomes at 30 days insufficiently describe recovery and that procedure-related morbidity and mortality continue to accrue for at least 90 days, challenging the paradigm of "30-day or in-hospital death" to define "operative mortality."

Pezzi and colleagues ${ }^{1}$ demonstrated that 90 -day mortality after resection for lung cancer is nearly double 30-day mortality in the National Cancer Database (30-day 2.8\%, 90-day 5.4\%). In another study from the National Cancer Database, of more than 300,000 patients with non-small cell lung cancer, the 90-day mortality was again almost double the 30-day mortality (30-day 3\%, 90-day $5.7 \%)^{2}$ While neither of these studies focused only on pneumonectomy, there is no reason to believe that pneumonectomy would be protective, as opposed to lobectomy. Finally, Hu and colleagues ${ }^{3}$ found that readmission after lung cancer resection is associated with a 6-fold increase in 90-day postoperative mortality in the Surveillance, Epidemiology, and End Results database.

The recent study from Memorial Sloan Kettering Cancer Center $^{4}$ analyzes outcomes after pneumonectomy, and the

From the Division of Thoracic Surgery, Department of Surgery, Duke University Medical Center, Durham, NC.

Disclosures: Author has nothing to disclose with regard to commercial support.

Received for publication March 10, 2020; revisions received March 10, 2020; accepted for publication March 11, 2020; available ahead of print April 5, 2020.

Address for reprints: Thomas A. D'Amico, MD, Section of General Thoracic Surgery,

Duke University Medical Center, DUMC Box 3496, Duke South, White Zone,

Room 3589, Durham, NC 27710 (E-mail: thomas.damico@ duke.edu).

J Thorac Cardiovasc Surg 2020;160:256-7

$0022-5223 / \$ 36.00$

Copyright (c) 2020 by The American Association for Thoracic Surgery

https://doi.org/10.1016/j.jtcvs.2020.03.115

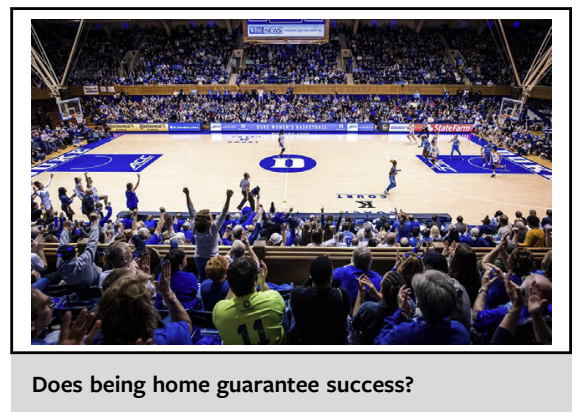

CENTRAL MESSAGE

Readmission after pneumonec-

tomy confers significant risk of

mortality until 90 days after sur-

gery. Failure to rescue is a result

of delayed readmission or inef-

fective care after readmission.

30-day threshold is again challenged. Interestingly, while the rates of pneumonectomy in this study decreased over time (perhaps owing to the effects of stage shift from lung cancer screening, awareness of the high mortality pneumonectomy, or other factors), the percentage of pneumonectomies after induction therapy-considered the most morbid-seems to have increased.

The 30-day mortality in this study was $4.5 \%$, and the critical analysis involves the follow-up of the patients who survived 30 days and the effect of the need for readmission on outcome. From 31 to 90 days after pneumonectomy, an additional $32(9.4 \%)$ patients were readmitted, and a total of $24(6.8 \%)$ patients died by 90 days. Importantly, 30 -day readmission of those 32 patients was associated with a substantially greater risk of 90-day mortality (odds ratio, 12.2), twice as high as the study by $\mathrm{Hu}$ and colleagues. ${ }^{3}$

All deaths before 90 days (24/24) were attributable to non-oncologic causes, and these deaths accounted for $73 \%$ of all non-oncologic deaths (24/33) during the first year after surgery.

Pulmonary causes were the most common cause for readmission after discharge, but it is unclear whether the readmissions were preventable or whether the deaths after readmissions were preventable. Finally, the overall risk of death was greatest immediately after surgery and fell to half by 7 days, but the ability to discharge patients still did not equate to 90 -day survival. 
In summary, this study confirms that pneumonectomy is associated with significant mortality, although lower in this series than in most in the literature. It also highlights the importance of using both 30-day and 90-day mortality after pneumonectomy in efforts to improve patient care and as a health care quality metric. Specifically, discharge survival at after 30 days is misleading in terms of health care and inaccurate as a quality measure. Readmission after pneumonectomy confers significant risk of mortality until at least 90 days after surgery, and additional investigation is required to determine which patients are not ready for discharge (despite meeting discharge criteria) and whether failure to rescue is a result of delayed readmission (due to either medical or non-medical factors) or insufficient care after readmission. Thus, patients are not home-free until they are home 90 days after pneumonectomy, and we are responsible for improving the decisions regarding discharge, readmission, and rescue.

\section{References}

1. Pezzi CM, Mallin K, Mendez AS, Greer GE, Putnam JB. Ninety-day mortality after resection for lung cancer is nearly double 30-day mortality. J Thorac Cardiovasc Surg. 2014;148:2269-77.

2. Moore CB, Cox ML, Mulvihill MS, Klapper J, D'Amico TA, Hartwig MG Challenging 30-day mortality as a site-specific quality metric in non-small cell lung cancer. J Thorac Cardiovasc Surg. 2019;158:570-8.

3. Hu Y, McMurry TL, Isbell JM, Stukenborg GJ, Kozower BD. Readmission following lung cancer resection is associated with a six-fold increase in 90-day postoperative mortality. J Thorac Cardiovasc Surg. 2014;148:2261-7.

4. Jones GD, Tan KS, Caso R, Dycoco J, Park BJ, Bott MJ, et al. Time-varying analysis of readmission and mortality during the first year after pneumonectomy. J Thorac Cardiovasc Surg. 2020;160:247-55.e5.
See Article page 247.

\section{Commentary: John Snow, pneumonectomy, and complication epidemiology}

\author{
Elliot Wakeam, MD, MPH
}

More than 150 years after John Snow used epidemiologic techniques to identify the origins of a London cholera outbreak and changed the face of modern epidemiology, little is known about the epidemiology of complications after surgery. Old adages like the "Rule of W" have predominated our thinking and teaching. Although some recent efforts have been made to try to use large data sets to study these phenomena, ${ }^{1}$ very little is actually known about the temporal occurrence patterns, severity, and sequelae of postoperative complications. Complications seem to come in waves, one thing after another, complications seemingly leading to more complications. Yet we've only started to scratch the surface in our understanding and quantification

\footnotetext{
From the Section of Thoracic Surgery, University of Michigan, Ann Arbor, Mich. Disclosures: Author has nothing to disclose with regard to commercial support. Received for publication March 14, 2020; revisions received March 14, 2020; accepted for publication March 16, 2020; available ahead of print April 6, 2020. Address for reprints: Elliot Wakeam, MD, MPH, Section of Thoracic Surgery, University of Michigan, Ann Arbor, MI 48102 (E-mail: elliot.wakeam@gmail.com). J Thorac Cardiovasc Surg 2020;160:257-8 $0022-5223 / \$ 36.00$

Copyright (c) 2020 by The American Association for Thoracic Surgery https://doi.org/10.1016/j.jtcvs.2020.03.110
}

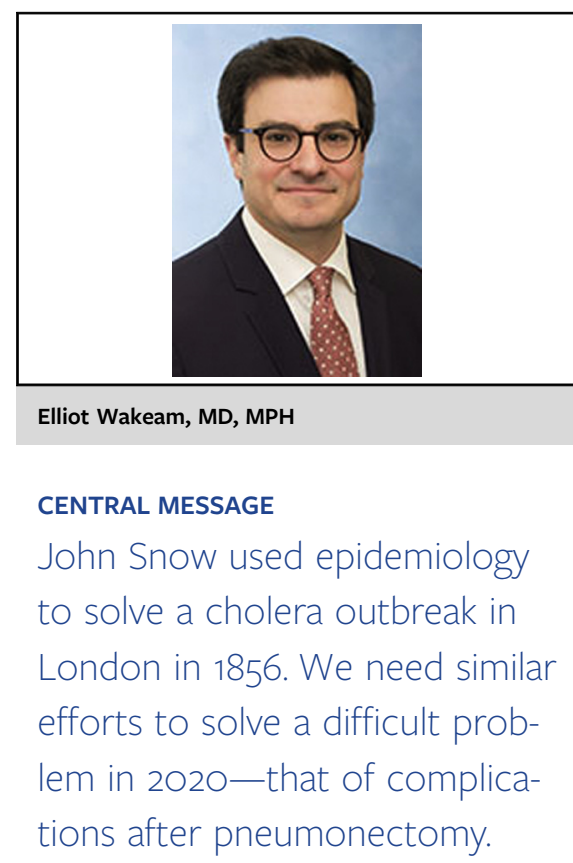

of how individual postoperative complications are linked together. $^{2}$

Jones and colleagues ${ }^{3}$ have made an effort to examine some of these phenomena in patients undergoing pneumonectomy at Memorial Sloan Kettering Cancer Center in New York. Pneumonectomy is an operation not only with high rates of complications but a specific risk profile and 